J. Lake Sci. (湖泊科学), 2013, 25(2): 199-208

http: //www. jlakes.org. E-mail : jlakes@niglas.ac.cn

(C) 2013 by Journal of Lake Sciences

\title{
太湖草/藻型湖区沉积物一水界面环境特征差异”
}

\author{
王永平 ${ }^{1,2}$, 朱广伟 ${ }^{2}$, 洪大林 $^{1}$, 秦伯强 ${ }^{2 * *}$ \\ (1: 南京水利科学研究院水文水资源与水利工程科学国家重点实验室,南京 210029) \\ (2: 中国科学院南京地理与湖泊研究所湖泊与环境国家重点实验室,南京 210008)
}

\begin{abstract}
摘 要: 在太湖草、藻型湖区进行冬、夏两季多点采样, 分别对采样点的水环境特征、泥面以上 $5 \mathrm{~cm}$ 上覆水中营养盐以及 沉积物的含水量、中值粒径、有机碳、氮、磷、金属元素和溶解氧进行测定. 结果表明: 夏季藻型湖区表层水体 $\mathrm{pH}$ 高于中、 底层, 冬季草型湖区各层水体 $\mathrm{pH}$ 高于藻型; 草型湖区水体浊度夏季低于藻型, 冬季反之; 藻型湖区上覆水中的硝态氮和 磷酸根浓度显著高于草型; 草型湖区沉积物中含水量冬季显著高于夏季; 草型湖区沉积物中总有机碳显著高于藻型; $\mathrm{Fe} 、$ $\mathrm{Zn} 、 \mathrm{Ca} 、 \mathrm{~Pb} 、 \mathrm{Na}$ 和 $\mathrm{K}$ 等元素在草、藻型湖区间差异显著; 沉积物中溶解氧表现为冬季深于夏季, 藻型深于草型的规律.
\end{abstract}

关键词: 沉积物一水界面; 草型湖区; 藻型湖区; 太湖

\section{Environmental characteristics of sediment-water interface of phytoplankton and macro- phyte dominated zones in Lake Taihu}

\author{
WANG Yongping ${ }^{1,2}$, ZHU Guangwei ${ }^{2}$, HONG Dalin ${ }^{1} \&$ QIN Boqiang ${ }^{2}$ \\ (1: State Key Laboratory of Hydrology-Water Resources and Hydraulic Engineering, Nanjing Hydraulic Research Institute, \\ Nanjing 210029, P. R. China) \\ (2: State Key Laboratory of Lake Science and Environment, Nanjing Institute of Geography and Limnology, Chinese Academy \\ of Sciences, Nanjing 210008, P. R. China)
}

\begin{abstract}
The investigation was conducted within large, shallow Lake Taihu, in winter and summer. 5 sites in phytoplankton dominated zone and 3 sites in macrophyte dominated zone were chosen for sampling. Parameters of sampling sites including water quality, nutrients concentrations in 5-cm overlaying water and vertical profiles of water content, mean value of grain size (D50), total organic carbon (TOC), nitrogen, phosphorus, metals and dissolved oxygen were analyzed. Results showed that, surface water $\mathrm{pH}$ in phytoplankton dominated zone was higher than that in the other two layers and water $\mathrm{pH}$ in winter was higher in macrophyte dominated zone than that in phytoplankton dominated zone; water nephelometric turbidity unites in macrophyte dominatd zone was higher than those in phytoplankton dominated zone in summer and contrarily in winter; concentrations of $\mathrm{NO}_{3}^{-}-\mathrm{N}$ and $\mathrm{PO}_{4}^{3-}-\mathrm{P}^{-}$of overlaying water were significantly higher in phytoplankton dominated zone than those in macrophyte dominated zone; sediment water contents in macrophyte dominated zone in winter was significant higher than those in summer; sediment TOC in macrophyte dominated zone was significant higher than that in phytoplankton dominated zone. There was significant difference of sediment metal concentration, including $\mathrm{Fe}, \mathrm{Zn}, \mathrm{Ca}, \mathrm{Pb}$, Na and $\mathrm{K}$ between macrophyte and phytoplankton dominated zone; oxygen penetration depths were deeper in winter than those in summer, and in phytoplankton dominated zone than in macrophyte dominated zone.
\end{abstract}

Keywords: Sediment-water interface; macrophyte dominated zone; phytoplankton dominated zone; Lake Taihu

沉积物一水界面一般是指新近沉降的 $15 \mathrm{~cm}$ 沉积物和附近的上覆水, 是天然水体在物理、化学和生物特 征等方面差异性最显著的、负责水体和沉积物之间物质输送与交换的重要边界环境, 也是控制和调节水体 和沉积物之间物质输送和交换的重要途径 ${ }^{[1]}$. 湖泊沉积物通常被认为是水体中营养盐、有机碳和其他许多

* 国家杰出青年基金项目 (40825004) 和湖泊与环境国家重点实验室开放基金项目联合资助. 2012 - 04-08 收稿; 2012-06-18 收修改稿. 王永平, 男,1982 年生, 博士,工程师;E-mail: will_yp@ 163. com.

** 通信作者;E-mail:qinbq@ niglas. ac. cn. 
物质的 “汇”. 在一定条件下, 沉积物中的有机物质和营养盐, 可以通过沉积物中微生物的作用, 被分解、矿 化, 使得营养盐和其他物质释放至孔隙水中 ${ }^{[2]}$, 如 $\mathrm{HCO}_{3}^{-} 、 \mathrm{Mn}^{2+} 、 \mathrm{NH}_{4}^{+} 、 \mathrm{Fe}^{2+} 、 \mathrm{H}_{2} \mathrm{~S}$ 和 $\mathrm{CH}_{4}$ 等 $^{[3]}$, 最后交换进人 湖泊水体中 ${ }^{[4]}$, 沉积物 - 水界面在其中起着至关重要的作用.

在不同环境条件下, 包括水动力和底栖生物等, 沉积物一水界面的性状亦有明显差异. 例如, 较强的水动 力能够引起沉积物一水界面发生侵蚀 ${ }^{[5]}$, 同时影响到沉积物表层的氧气侵蚀深度 ${ }^{[6]}$. 底栖生物带来的生物扰 动也能改变沉积物初级结构 ${ }^{[7]}$, 影响界面上有机质分解和矿化等生物地球化学过程 ${ }^{[8]}$. 不同的生物群落对 沉积物一水界面营养盐迁移转化效率的影响亦不相同 ${ }^{[9-10]}$. 草型湖区和藻型湖区的生态系统和环境条件差异 明显, 特别是大型水生植物根部可以通过释放氧气或者呼吸作用吸收氧气而改变沉积物一水界面氧化还原

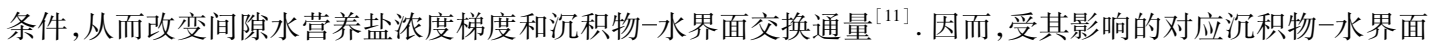
环境也有不同, 张路等研究了草、藻型湖区沉积物表层 $25 \mathrm{~cm}$ 左右间隙水和沉积物理化指标差异 ${ }^{[12]}$, 也有学 者研究了界面附近的大型底栖动物群落结构 ${ }^{[13]}$ 和固着藻类的分布特征 ${ }^{[14]}$. 然而, 关于草、藻型湖区沉积物 水界面自身结构的差异尚少见报道.

太湖是我国东部营养程度和水污染较为严重的湖泊, 因其典型的大型浅水湖泊特征和 2007 年发生的 蓝藻 “水危机” 事件而深受世界的关注. 同时, 由于太湖面积大、环境复杂, 特别是草、藻型湖区特征明显, 为 开展本研究提供了非常理想的场所. 因此, 本研究分别于冬、夏两季在太湖草、藻型湖区进行多点采样, 以求 弄清在以浮游植物和水生植物为主导的生态系统影响下的沉积物一水界面的环境特征差异, 以及蓝藻暴发 和水生植物生长与界面特征差异的关系, 从而为弄清浅水湖泊内源污染和开展生态修复提供理论依据.

\section{1 材料与方法}

\section{1 采样点}

本研究在太湖的藻型湖区布设 5 个样点 (用 $\boldsymbol{\Delta}$ 表示), 在草型湖区布设 3 个样点 (用一表示), 分别在夏 季和冬季进行采样 (图 1). 其中, 夏季时藻型湖区蓝藻水华暴发严重, 草型湖区水草生长茂盛; 冬季时蓝藻和 水草都基本消失.

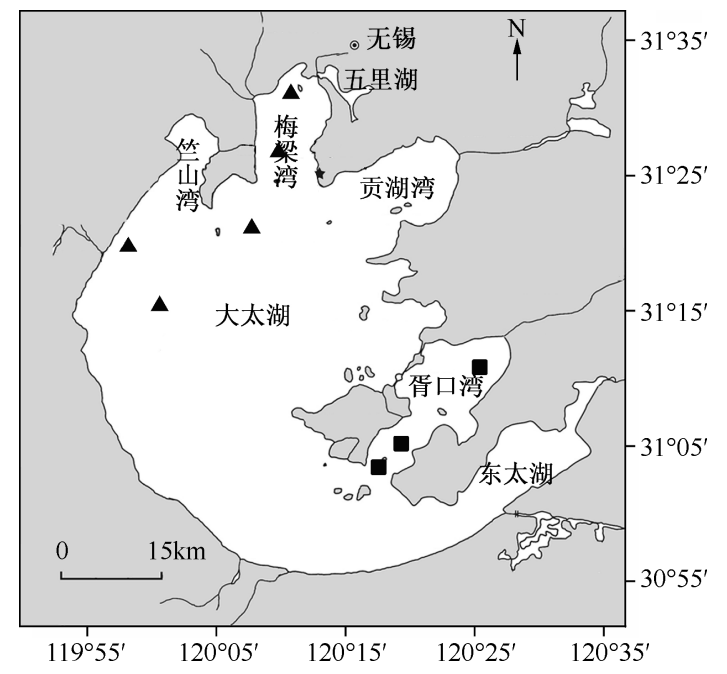

图 1 太湖采样点分布

Fig. 1 Distribution of sampling sites in Lake Taihu

\section{2 采样程序}

采样工作分别于 2010 年 1 月和 7 月进行, 先使用 YSI 6600 V2 型多参数水质监测仪 (美国) 现场记录 表、中、底 3 层水体的水质参数, 然后用手持式沉积物泥芯采样器采集沉积物柱状样, 上下密封后带回实验 室, 尽量不扰动界面. 


\section{3 界面溶解氧层的测定}

界面溶解氧层的测定采用溶氧微电极 (PreSens, 德国) 进行. 电极的有效测定区小于 $20 \mu \mathrm{m}$, 涂有固态光敏 苂光粉; 在 $0 \sim 100 \%$ 空气饱和度水体中, 氧气浓度与光强呈线性关系; 电极反应时间小于 $1 \mathrm{~s}$. 使用前采用饱和 空气 ( $100 \%$ 氧气) 和饱和 $\mathrm{Na}_{2} \mathrm{SO}_{3}$ 溶液 ( $0 \%$ 氧气) 进行两点校准. 试验时, 将微电极安装在微电极操作器上, 裸 眼利用放大镜确定水土界面后, 每隔 $0.2 \mathrm{~mm}$ 下移一次进行连续测定, 直至氧气含量减少到 $0 \mathrm{mg} / \mathrm{L}$ 为止.

\section{4 水样采集与分析}

用虹吸法小心吸取柱状样泥面以上 $5 \mathrm{~cm}$ 以内上覆水, 经 Whatman $\mathrm{GF} / \mathrm{C}$ 膜过滤后, 一部分用 Skalar 流 动分析仪测定铵态氮、硝态氮、亚硝态氮和磷酸根浓度; 另一部分用 TOC-V CPN (Japan, SHIMADZU) 测定溶 解性有机碳 (DOC).

\section{5 泥样分析}

沉积物柱状样按照靠界面近密远疏的原则, 从上往下共 $15 \mathrm{~cm}$ 按照 $0.5 、 0.5 、 0.5 、 0.5 、 0.5 、 0.5 、 1 、 1 、 1 、$ $2 、 2$ 和 $5 \mathrm{~cm}$ 进行分层. 新鲜沉积物样一部分经 $103 \sim 105^{\circ} \mathrm{C}$ 烘烤约 $24 \mathrm{~h}$ 至恒重, 用以计算含水率; 另一部分由 英国 Malvern 公司的 Masterisizer 2000 型激光粒度仪分析粒度. 剩下的沉积物样自然风干, 经玛瑙研钵研磨, 过 200 目篮后,一部分用王水消解, 由 ICP-AES 测定 $\mathrm{Al} 、 \mathrm{Ca} 、 \mathrm{Mn} 、 \mathrm{Fe} 、 \mathrm{Mg} 、 \mathrm{~K} 、 \mathrm{~Pb} 、 \mathrm{Na} 、 \mathrm{P} 、 \mathrm{Zn} 、 \mathrm{Cu}$ 等元素含量; 另一 部分由 EA3000 型元素分析仪测定总氮和总有机碳.

\section{2 结果与分析}

\section{1 采样点的水环境特征}

相同湖区和季节条件下,表、中、底 3 层水体间大部分指标都没有表现出明显差异. 差异主要体现在:夏 季藻型湖区表层 $\mathrm{pH}$ 明显高于中层和底层; 夏季两个湖区水体中溶解氧 ( DO) 的含量与饱和度都呈现出随深 度加深而减少的趋势 (表 1 )。

在相同季节内, 两个湖区间的 $\mathrm{pH}$ 、氧化还原电位 $(\mathrm{ORP})$ 和浊度等指标也存在差异, 具体表现为: 冬季草 型湖区各层水体 $\mathrm{pH}$ 都高于藻型湖区; 冬、夏两季藻型湖区各层水体 ORP 和电导率 (EC) 都略高于草型; 浊度 则是在冬季草型湖区高于藻型湖区, 夏季藻型湖区高于草型湖区 (表 1 ).

同一湖区在不同季节间也存在差异. 两类湖区的共同特征是水体温度夏季高冬季低, 而 EC、浊度和溶 解氧则是冬季高、夏季低, 季节性明显. 另外, 夏季藻型湖区水体的 $\mathrm{pH}$ 明显高于冬季(表 1 ).

表 1 太湖采样点现场水环境特征

Tab. 1 Characteristics of water columns at sampling sites in Lake Taihu

\begin{tabular}{|c|c|c|c|c|c|c|c|c|c|c|c|c|}
\hline \multirow{3}{*}{ 指标 } & \multicolumn{6}{|c|}{ 冬季 } & \multicolumn{6}{|c|}{ 夏季 } \\
\hline & \multicolumn{3}{|c|}{ 藻型湖区 } & \multicolumn{3}{|c|}{ 草型湖区 } & \multicolumn{3}{|c|}{ 藻型湖区 } & \multicolumn{3}{|c|}{ 草型湖区 } \\
\hline & 表层 & 中层 & 底层 & 表层 & 中层 & 底层 & 表层 & 中层 & 底层 & 表层 & 中层 & 底层 \\
\hline $\mathrm{T} /{ }^{\circ} \mathrm{C}$ & $\begin{array}{l}6.57 \\
\pm 0.40\end{array}$ & $\begin{array}{c}6.56 \\
\pm 0.42\end{array}$ & $\begin{array}{l}6.57 \\
\pm 0.42\end{array}$ & $\begin{array}{l}6.41 \\
\pm 0.02\end{array}$ & $\begin{array}{c}6.41 \\
\pm 0.02\end{array}$ & $\begin{array}{c}6.42 \\
\pm 0.02\end{array}$ & $\begin{array}{l}26.36 \\
\pm 0.37\end{array}$ & $\begin{array}{l}26.12 \\
\pm 0.44\end{array}$ & $\begin{array}{l}26.06 \\
\pm 0.50\end{array}$ & $\begin{array}{l}26.20 \\
\pm 0.16\end{array}$ & $\begin{array}{l}26.21 \\
\pm 0.15\end{array}$ & $\begin{array}{l}26.16 \\
\pm 0.08\end{array}$ \\
\hline $\begin{array}{c}\mathrm{EC} / \\
(\mathrm{mS} / \mathrm{cm})\end{array}$ & $\begin{array}{c}0.57 \\
\pm 0.06\end{array}$ & $\begin{array}{c}0.57 \\
\pm 0.06\end{array}$ & $\begin{array}{l}0.57 \\
\pm 0.05\end{array}$ & $\begin{array}{l}0.51 \\
\pm 0.03\end{array}$ & $\begin{array}{c}0.52 \\
\pm 0.04\end{array}$ & $\begin{array}{l}0.51 \\
\pm 0.03\end{array}$ & $\begin{array}{l}0.48 \\
\pm 0.05\end{array}$ & $\begin{array}{l}0.48 \\
\pm 0.05\end{array}$ & $\begin{array}{l}0.48 \\
\pm 0.05\end{array}$ & $\begin{array}{l}0.46 \\
\pm 0.05\end{array}$ & $\begin{array}{l}0.46 \\
\pm 0.05\end{array}$ & $\begin{array}{l}0.46 \\
\pm 0.04\end{array}$ \\
\hline $\mathrm{pH}$ & $\begin{array}{l}7.91 \\
\pm 0.48\end{array}$ & $\begin{array}{l}7.96 \\
\pm 0.46\end{array}$ & $\begin{array}{l}7.98 \\
\pm 0.42\end{array}$ & $\begin{array}{l}8.25 \\
\pm 0.03\end{array}$ & $\begin{array}{l}8.22 \\
\pm 0.01\end{array}$ & $\begin{array}{l}8.23 \\
\pm 0.02\end{array}$ & $\begin{array}{l}8.50 \\
\pm 0.38\end{array}$ & $\begin{array}{l}8.37 \\
\pm 0.29\end{array}$ & $\begin{array}{l}8.32 \\
\pm 0.28\end{array}$ & $\begin{array}{l}8.23 \\
\pm 0.17\end{array}$ & $\begin{array}{l}8.21 \\
\pm 0.27\end{array}$ & $\begin{array}{l}8.17 \\
\pm 0.31\end{array}$ \\
\hline ORP & $\begin{array}{l}493.82 \\
\pm 135.46\end{array}$ & $\begin{array}{c}477.74 \\
\pm 108.83\end{array}$ & $\begin{array}{l}476.64 \\
\pm 115.28\end{array}$ & $\begin{array}{l}411.40 \\
\pm 43.15\end{array}$ & $\begin{array}{l}406.45 \\
\pm 53.53\end{array}$ & $\begin{array}{l}397.60 \\
\pm 46.90\end{array}$ & $\begin{array}{l}476.40 \\
\pm 219.87\end{array}$ & $\begin{array}{l}600.00 \\
\pm 205.91\end{array}$ & $\begin{array}{l}659.40 \\
\pm 200.59\end{array}$ & $\begin{array}{l}348.00 \\
\pm 53.11\end{array}$ & $\begin{array}{l}449.00 \\
\pm 88.45\end{array}$ & $\begin{array}{l}402.67 \\
\pm 135.02\end{array}$ \\
\hline 浊度 & $\begin{array}{c}72.16 \\
\pm 72.16\end{array}$ & $\begin{array}{c}72.94 \\
\pm 72.67\end{array}$ & $\begin{array}{c}77.96 \\
\pm 72.78\end{array}$ & $\begin{array}{l}155.03 \\
\pm 87.87\end{array}$ & $\begin{array}{c}107.85 \\
\pm 103.45\end{array}$ & $\begin{array}{l}157.30 \\
\pm 97.80\end{array}$ & $\begin{array}{c}30.16 \\
\pm 16.08\end{array}$ & $\begin{array}{l}22.40 \\
\pm 6.90\end{array}$ & $\begin{array}{l}43.64 \\
\pm 22.53\end{array}$ & $\begin{array}{l}1.53 \\
\pm 2.31\end{array}$ & $\begin{array}{l}3.20 \\
\pm 1.18\end{array}$ & $\begin{array}{l}4.60 \\
\pm 1.14\end{array}$ \\
\hline $\begin{array}{c}\text { DO/ } \\
\%\end{array}$ & $\begin{array}{l}94.58 \\
\pm 11.85\end{array}$ & $\begin{array}{l}94.14 \\
\pm 12.44\end{array}$ & $\begin{array}{l}93.72 \\
\pm 12.61\end{array}$ & $\begin{array}{l}96.40 \\
\pm 0.72\end{array}$ & $\begin{array}{l}95.50 \\
\pm 1.13\end{array}$ & $\begin{array}{l}95.97 \\
\pm 0.95\end{array}$ & $\begin{array}{l}107.88 \\
\pm 14.63\end{array}$ & $\begin{array}{l}96.52 \\
\pm 4.00\end{array}$ & $\begin{array}{l}93.18 \\
\pm 4.52\end{array}$ & $\begin{array}{l}92.87 \\
\pm 6.35\end{array}$ & $\begin{array}{l}89.77 \\
\pm 4.51\end{array}$ & $\begin{array}{l}83.87 \\
\pm 2.89\end{array}$ \\
\hline $\begin{array}{c}\mathrm{DO} / \\
(\mathrm{mg} / \mathrm{L})\end{array}$ & $\begin{array}{l}11.59 \\
\pm 1.55\end{array}$ & $\begin{array}{l}11.54 \\
\pm 1.61\end{array}$ & $\begin{array}{l}11.49 \\
\pm 1.64\end{array}$ & $\begin{array}{l}11.86 \\
\pm 0.08\end{array}$ & $\begin{array}{l}11.74 \\
\pm 0.14\end{array}$ & $\begin{array}{l}11.80 \\
\pm 0.12\end{array}$ & $\begin{array}{l}8.68 \\
\pm 1.16\end{array}$ & $\begin{array}{l}7.80 \\
\pm 0.36\end{array}$ & $\begin{array}{l}7.54 \\
\pm 0.37\end{array}$ & $\begin{array}{l}7.50 \\
\pm 0.52\end{array}$ & $\begin{array}{l}7.25 \\
\pm 0.37\end{array}$ & $\begin{array}{l}6.78 \\
\pm 0.24\end{array}$ \\
\hline
\end{tabular}




\section{2 上覆水营养盐浓度差异}

草、藻型湖区上覆水中铵态氮和 DOC 在冬、夏两季都没有显著性差异, 而藻型湖区上覆水中的硝态氮和 磷酸根在冬、夏两季都显著高于草型湖区 $(P<0.05)$. 另外, 藻型湖区上覆水中的亚硝态氮仅在夏季显著高 于草型湖区, 冬季时差异不显著. 同一湖区的大部分指标在季节间都没有显著性差异, 只有 DOC 和藻型湖区 的硝态氮浓度存在季节性差异, 并且都是冬季高于夏季. 除 DOC 外, 各项营养盐指标都显示出草、藻型湖区 自身各点位的差异也较大(图 2).
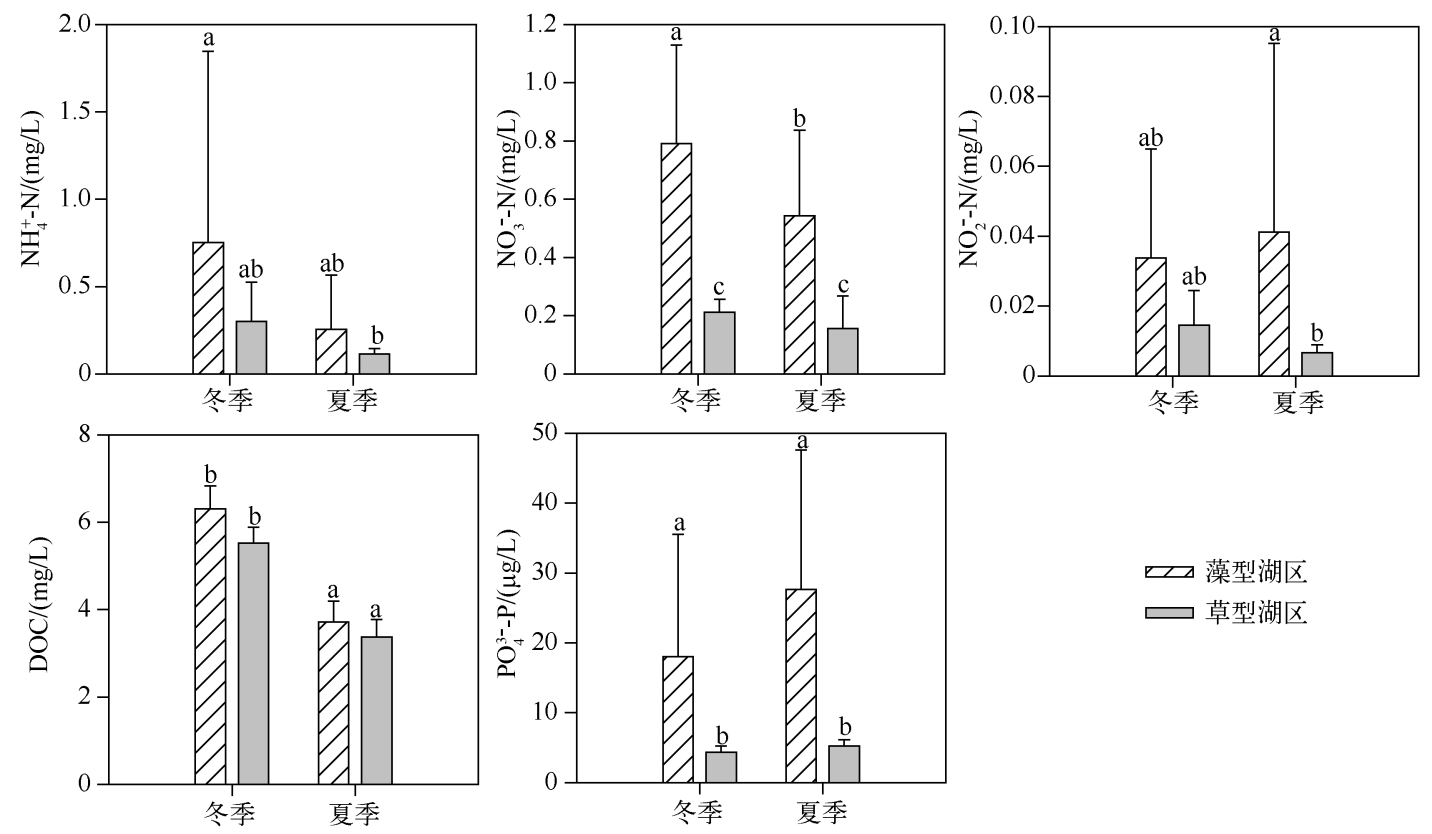

图 2 沉积物一水界面 $5 \mathrm{~cm}$ 内上覆水中铵态氮、硝态氮、亚硝态氮、磷酸根和溶解性有机碳含量

（误差线代表标准误差,不同的小写字母表示存在显著性差异 $(P<0.05)$,下同)

Fig. 2 Concentrations of $\mathrm{NH}_{4}^{+}-\mathrm{N}, \mathrm{NO}_{3}^{-}-\mathrm{N}, \mathrm{NO}_{2}^{-}-\mathrm{N}, \mathrm{PO}_{4}^{3-}-\mathrm{P}$ and $\mathrm{DOC}$ in $5 \mathrm{~cm}$ overlaying water

表 2 草、藻型湖区冬、夏两季沉积物含水量和 D50 中值粒径的差异 ${ }^{*}$

Tab. 2 Differences of water content and mean value of grain size of sediment in macrophytes and phytoplankton dominated zones in winter and spring

\begin{tabular}{ccc}
\hline 湖区类型 & 含水量 $/ \%$ & $\begin{array}{c}\text { 中值粒径 }(\mathrm{D} 50) / \\
\left(\times 10^{-3} \mathrm{~mm}\right)\end{array}$ \\
\hline 冬季藻型 & $56.81 \pm 10.02^{\mathrm{a}}$ & $11.35 \pm 1.86^{\mathrm{a}}$ \\
夏季藻型 & $58.96 \pm 8.88^{\mathrm{a}}$ & $11.41 \pm 1.09^{\mathrm{a}}$ \\
冬季草型 & $69.20 \pm 6.62^{\mathrm{b}}$ & $12.15 \pm 3.49^{\mathrm{ab}}$ \\
夏季草型 & $60.39 \pm 5.42^{\mathrm{a}}$ & $12.68 \pm 2.59^{\mathrm{b}}$ \\
\hline
\end{tabular}

* 藻型湖区 60 个样本, 草型湖区 36 个样本. 值 由平均值 \pm 标准误差组成, 不同字母表示存在显 著性差异 $(P<0.05)$,下同.

\section{3 沉积物物理性状垂直分布}

草、藻型湖区沉积物的含水量都有随深度增加 而逐渐减少的趋势, 并且拐点都出现在 $3 \mathrm{~cm}$ 深度左 右(图 3). 由单因素方差分析可知, 藻型湖区沉积物 的含水量不存在季节性差异, 而在草型湖区, 沉积物 的含水量在冬季显著高于夏季 (表 2).

藻型湖区沉积物的 D50 中值粒径的垂向分布在 冬、夏两季都保持稳定, 没有明显差异. 而草型湖区 沉积物的 D50 中值粒径垂向分布变化幅度较大, 且 冬季的变化幅度大于夏季. 同时, 各采样点间的差异 也较为明显. 方差分析结果显示, 草、藻型湖区的 D50 中值粒径在夏季存在显著性差异, 且草型高于藻 型(表 2).

\section{4 沉积物化学性状垂直分布}

除夏季草型湖区沉积物中总有机碳在 $6 \mathrm{~cm}$ 深度 处出现拐点下降外, 沉积物中总有机碳含量在垂直 


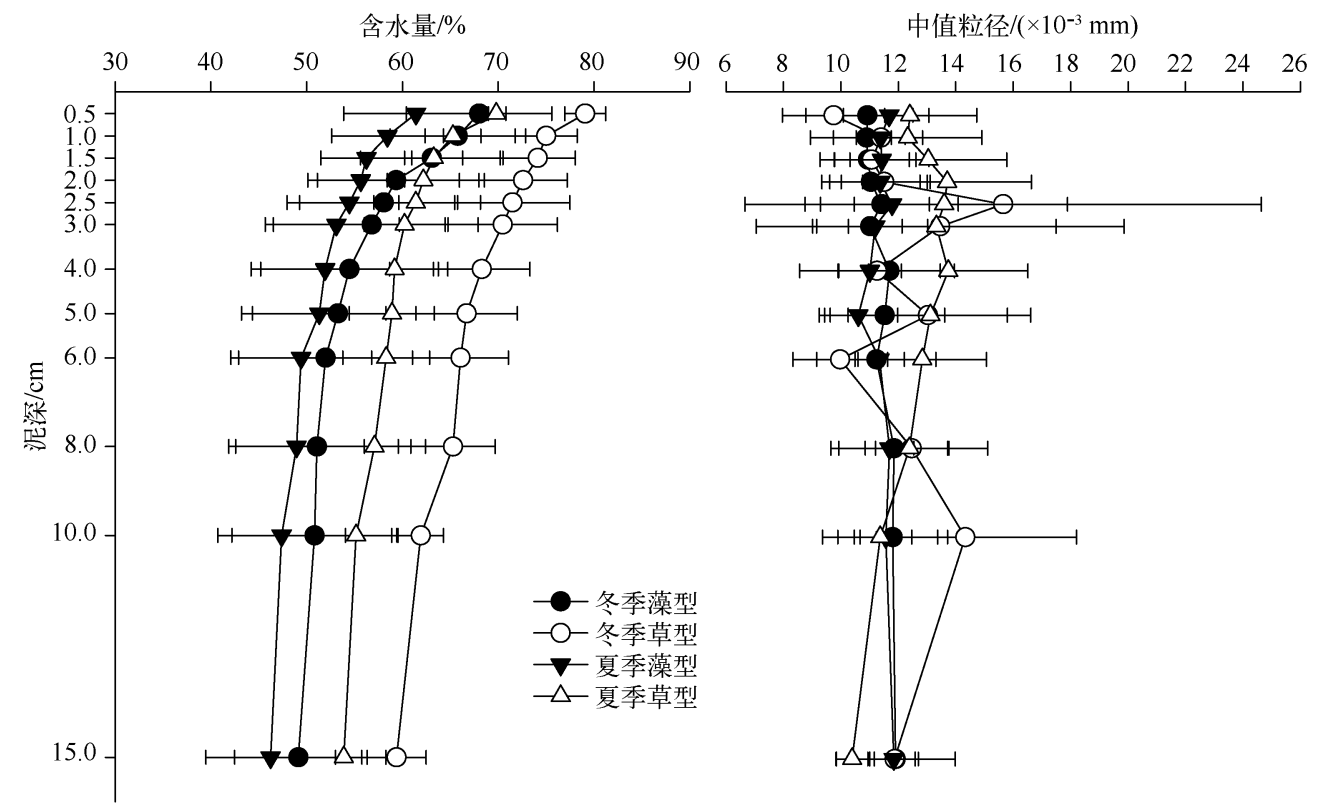

图 3 草、藻型湖区沉积物含水量和 D50 中值粒径垂直分布

Fig. 3 Vertical profiles of water content and mean value of grain size of sediment in macrophytes and phytoplankton dominated zones

方向上总体而言没有出现明显的波动 (图 4). 但是, 湖区间和季节间都呈现出显著性差异. 其中, 草型湖区沉 积物中总有机碳在冬、夏两季都显著高于藻型湖区. 同时, 两个湖区沉积物中的总有机碳季节差异明显, 且 都是冬季显著高于夏季 (表 3 ).

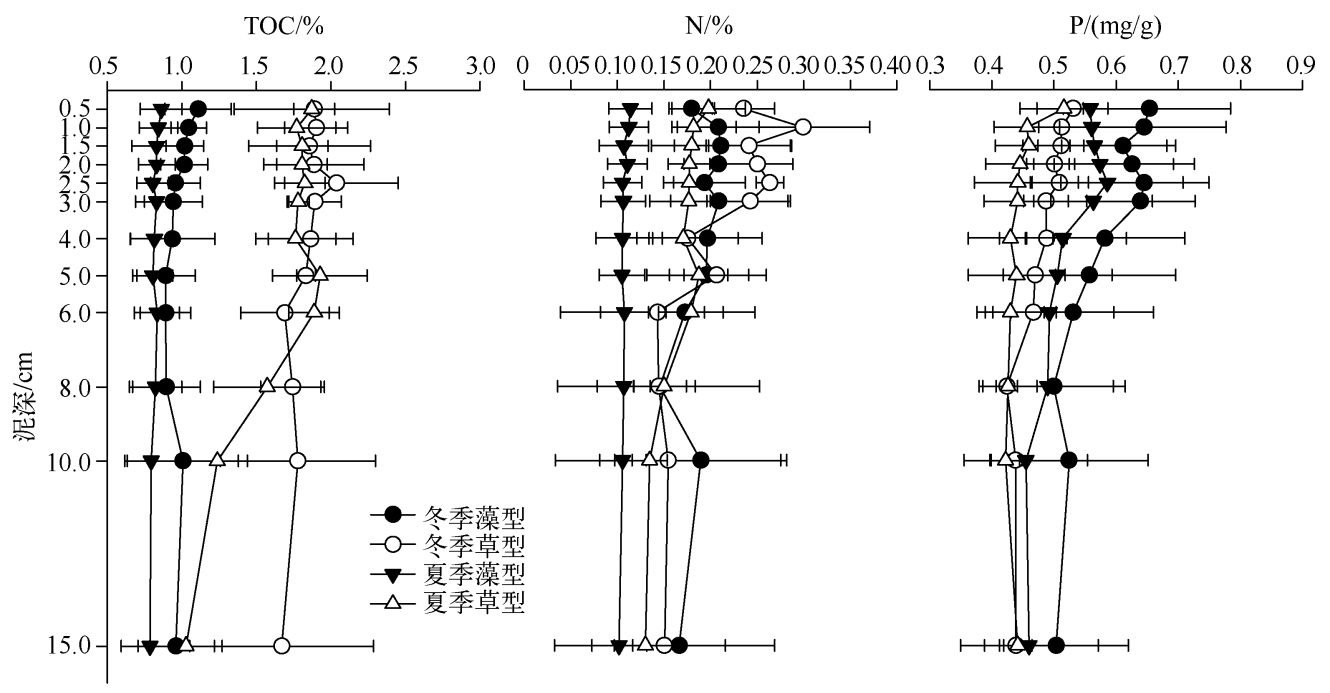

图 4 草、藻型湖区沉积物 TOC、N 和 P 的垂直分布

Fig. 4 Vertical profiles of TOC, N and P of sediment in macrophytes and phytoplankton dominated zones

沉积物中总氮和总磷的垂直分布大致呈随深度变浅浓度升高的趋势. 而在表层 $3 \mathrm{~cm}$ 内, 情况较为复杂, 具体表现为: 草、藻型湖区表层 $0.5 \mathrm{~cm}$ 沉积物中氮的含量明显低于以下各层; 藻型湖区表层 $3 \mathrm{~cm}$ 沉积物中 
表 3 草、藻型湖区冬、夏两季沉积物营养盐含量的差异

Tab. 3 Differences of nutrients profiles in the sediment in macrophytes and phytoplankton dominated zones

in winter and spring

\begin{tabular}{cccc}
\hline 湖区类型 & TOC $/ \%$ & $\mathrm{~N} / \%$ & $\mathrm{P} /(\mathrm{mg} / \mathrm{g})$ \\
\hline 冬季藻型 & $0.974 \pm 0.207^{\mathrm{a}}$ & $0.190 \pm 0.053^{\mathrm{bc}}$ & $0.585 \pm 0.120^{\mathrm{a}}$ \\
夏季藻型 & $0.823 \pm 0.137^{\mathrm{b}}$ & $0.108 \pm 0.023^{\mathrm{a}}$ & $0.527 \pm 0.103^{\mathrm{b}}$ \\
冬季草型 & $1.838 \pm 0.302^{\mathrm{c}}$ & $0.209 \pm 0.081^{\mathrm{b}}$ & $0.482 \pm 0.041^{\mathrm{c}}$ \\
夏季草型 & $1.686 \pm 0.341^{\mathrm{d}}$ & $0.169 \pm 0.030^{\mathrm{c}}$ & $0.444 \pm 0.050^{\mathrm{c}}$ \\
\hline
\end{tabular}

总磷随深度变浅, 浓度也逐渐降低. 在相 同季节内, 沉积物中总氮在藻型湖区低于 草型湖区, 而总磷则是在藻型湖区高于草 型湖区. 草、藻型湖区沉积物内总氮含量 都存在季节性差异, 且都是冬季高于夏 季, 特别是夏季藻型湖区, 其沉积物中总 氮含量显著低于其它季节和湖区. 藻型湖 区沉积物中的总磷含量也呈现出相似的 趋势, 冬季显著高于夏季, 而草型湖区未 见季节性差异 (图 4, 表 3).

草、藻型湖区冬夏季沉积物中除 Mn 随深度加深含量逐渐降低外, 其余各元素含量与深度都没有明显相 关. 总体而言, 藻型湖区几乎所有元素的季节性差异都不明显. 而在草型湖区, 沉积物中 $\mathrm{Fe} 、 \mathrm{Na} 、 \mathrm{Al}$ 和 $\mathrm{Mg}$ 元 素在冬、夏两季间都存在显著性差异. 另外, 同一季节中 $\mathrm{Fe} 、 \mathrm{Zn} 、 \mathrm{Ca} 、 \mathrm{~Pb} 、 \mathrm{Na}$ 和 $\mathrm{K}$ 等元素在草、藻型湖区间差异 显著(图 5 ,表 4 ).

表 4 草、藻型湖区冬、夏两季沉积物金属元素含量的差异

Tab. 4 Differences of sediment metals in macrophytes and phytoplankton dominated zones in winter and spring

\begin{tabular}{|c|c|c|c|c|c|c|c|c|c|}
\hline 湖区类型 & $\mathrm{Fe}$ & Mn & $\mathrm{Zn}$ & $\mathrm{Ca}$ & $\mathrm{Pb}$ & $\mathrm{Na}$ & $\mathrm{Al}$ & $\mathrm{Mg}$ & K \\
\hline 冬季藻型 & $34.44 \pm 4.64^{\mathrm{a}}$ & $0.827 \pm 0.256^{\mathrm{a}} 1$ & $109.5 \pm 29.2^{\mathrm{a}}$ & $6.13 \pm 1.05^{\mathrm{a}}$ & $38.75 \pm 5.11^{\mathrm{a}}$ & $10.37 \pm 0.88^{\mathrm{c}}$ & $59.28 \pm 6.31^{\mathrm{bc}}$ & $5.82 \pm 0.51^{\mathrm{b}}$ & $14.48 \pm 0.58^{\mathrm{a}}$ \\
\hline 夏季藻型 & $33.15 \pm 2.49^{\mathrm{ab}}$ & $0.739 \pm 0.213^{\mathrm{ab}}$ & $93.0 \pm 32.5^{\mathrm{b}}$ & $4.76 \pm 0.73^{\mathrm{a}}$ & $37.32 \pm 4.10^{\mathrm{a}}$ & $10.34 \pm 0.83^{\mathrm{c}}$ & $56.51 \pm 4.00^{\mathrm{ab}}$ & $5.70 \pm 0.43^{\mathrm{ab}}$ & $14.34 \pm 0.99^{\mathrm{a}}$ \\
\hline 冬季草型 & $32.65 \pm 2.35^{\mathrm{b}}$ & $0.726 \pm 0.263^{\mathrm{ab}}$ & $91.3 \pm 7.4^{\mathrm{b}}$ & $12.05 \pm 6.80^{\mathrm{b}}$ & $48.72 \pm 7.58^{\mathrm{b}}$ & $9.09 \pm 0.82^{\mathrm{b}}$ & $61.21 \pm 9.11^{\mathrm{c}}$ & $5.79 \pm 0.48^{\mathrm{b}}$ & $14.93 \pm 0.62^{\mathrm{b}}$ \\
\hline 夏季草型 & $30.61 \pm 4.67^{\mathrm{c}}$ & $0.663 \pm 0.218^{b}$ & $84.1 \pm 14.1^{\mathrm{b}}$ & $11.09 \pm 4.50^{\mathrm{b}}$ & $48.20 \pm 8.74^{b}$ & $8.64 \pm 0.68^{\mathrm{a}}$ & $55.88 \pm 7.95^{\mathrm{a}}$ & $5.46 \pm 0.90^{\mathrm{a}}$ & $14.58 \pm 1.54^{\mathrm{ab}}$ \\
\hline
\end{tabular}

草、藻型湖区冬夏季沉积物界面溶氧层呈现出相同湖区中冬季显著深于夏季, 相同季节时藻型湖区沉 积物界面溶氧层显著深于草型湖区的规律 (图 6).

\section{3 讨论}

\section{1 草藻型湖区沉积物一水界面特征差异}

大量研究表明, 蓝藻水华能显著改变水体中 $\mathrm{pH}$ 并刺激沉积物中溶解性营养盐的释放 ${ }^{[15-16]}$. 浮游藻类沉 降在沉积物表面并发生矿化 ${ }^{[17-19]}$, 能影响沉积物一水界面的溶解氧; 侵蚀深度和营养盐通量, 同时对沉积物 表层细菌活性也产生影响 ${ }^{[20]}$. 而水生植物特别是沉水植物、挺水植物生长茂盛的湖泊抗风浪及促沉积、恢复 能力均较强. 其根系深人沉积物中, 能直接引起沉积物性质的改变. 另外, 水生植物处于氧化状态根际微环 境能促进金属离子从还原态转为氧化态, 如将 $\mathrm{Mn}^{2+} 、 \mathrm{Fe}^{2+}$ 氧化, 形成铁锰氧化膜, 从而能极显著地增加土壤 对磷的吸附 ${ }^{[21-22]}$. 水生植物根际还能形成特殊的生态环境, 从而为大量需氧微生物群生长繁殖提供良好的 生境,加速有机物的分解 ${ }^{[23]}$.

本研究中, 草和藻的存在使太湖不同区域产生了诸多差异. 首先, 草和藻的存在引起不同湖区水质指标的 差异. 夏季藻型湖区蓝藻水华严重, 受蓝藻光合作用影响, 表层水体的溶解氧和 $\mathrm{pH}$ 显著升高. 而夏季草型湖区 由于水生植物的存在, 消浪作用明显, 透明度远高于藻型湖区, 表现为浊度显著低于藻型湖区. 并且, 由于夏季 受水生植物的保护, 草型湖区的风浪很难引起沉积物的再悬浮, 而在冬季没有水生植物保护时, 表层沉积物积 累的大量悬浮物一起释放, 反而使草型湖区的水体比藻型湖区更浑浊,表现为浊度高于藻型湖区.

其次, 水生植物能通过根系吸收沉积物中的生物有效磷, 有效减少沉积物间隙水中的磷向上覆水的扩 散量; 还通过茎叶拦截、吸附水中的颗粒物质并且通过颗粒物质吸附水中的可溶性磷, 有效地降低上覆水水 中的磷及颗粒物的负荷 ${ }^{[24]}$. 本研究, 同样可以观察到藻型湖区界面上覆水中的硝态氮和磷酸根在冬、夏两季 都显著高于草型湖区.

第三, 草和藻的存在造成了沉积物理化性质的差异. 不同种水生植物死亡后沉降到沉积物表面发生矿 

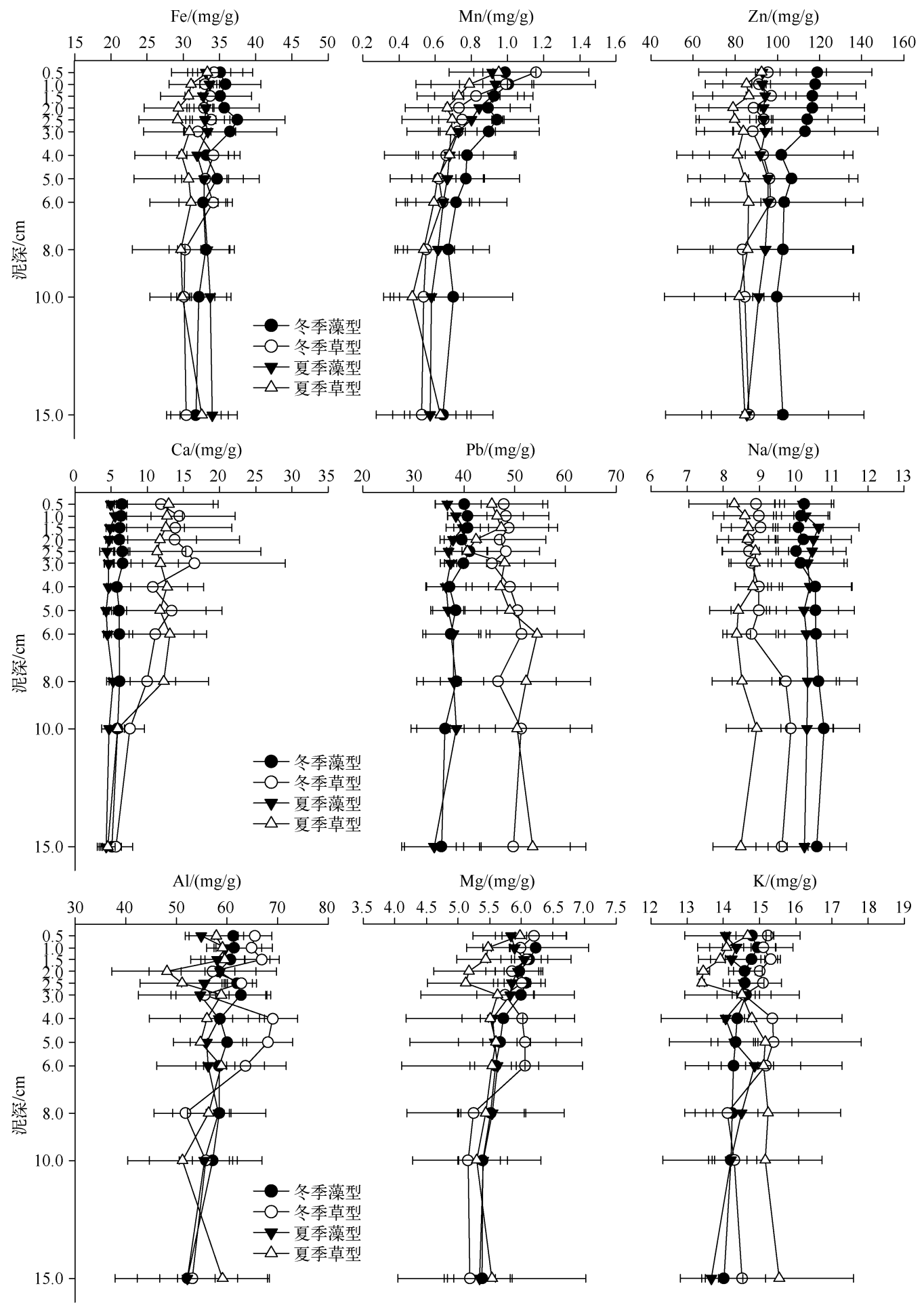

$\mathrm{Mg} /(\mathrm{mg} / \mathrm{g})$

$\mathrm{K} /(\mathrm{mg} / \mathrm{g})$

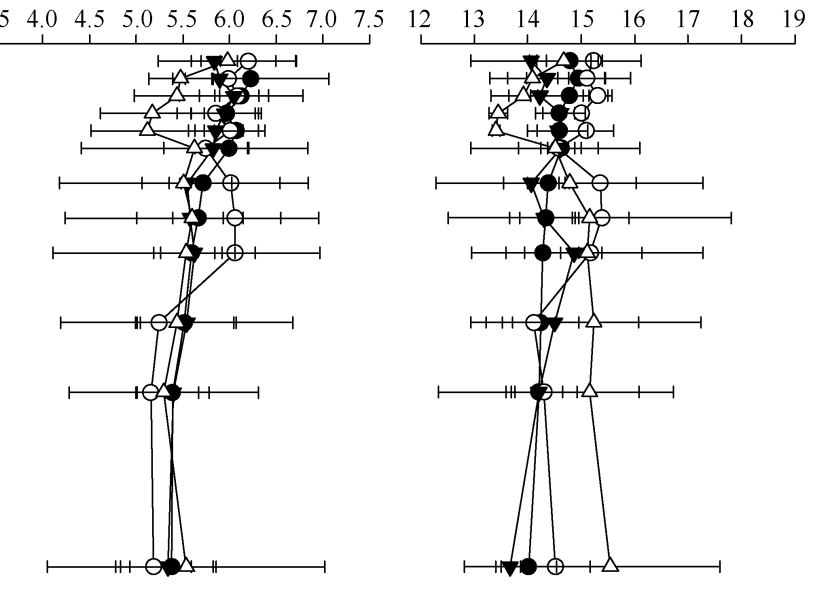

图 5 草、藻型湖区沉积物金属元素垂直分布

Fig. 5 Vertical profiles of sediment metals in macrophytes and phytoplankton dominated zones 


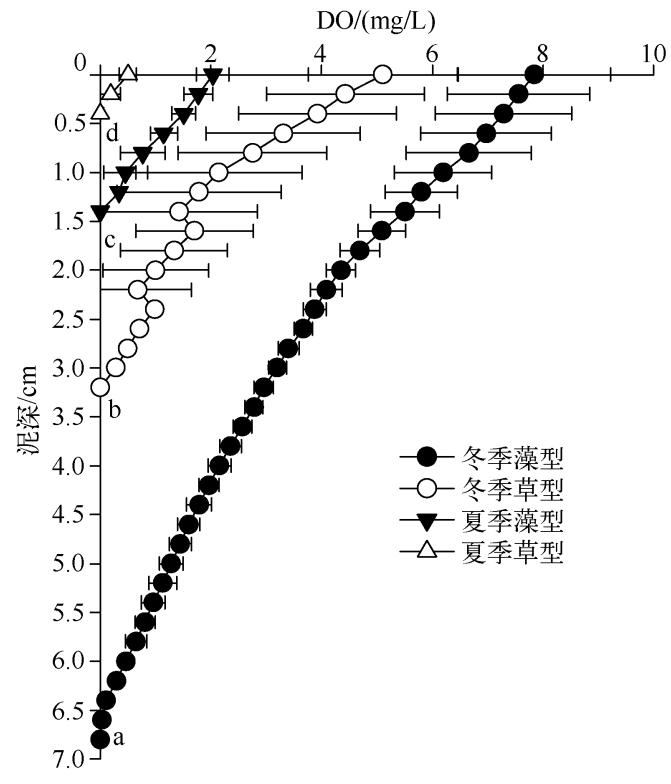

图 6 草、藻型湖区沉积物氧气侵蚀深度

Fig. 6 Oxygen penetration depth of macrophytes and phytoplankton dominated zones
化和成岩作用, 导致草型湖区不同采样点的 D50 中值 粒径差异较大. 同时水生植物死亡后沉降到沉积物表 面, 造成草型湖区沉积物中总有机碳显著高于藻型湖 区, 并且由于微生物腐烂分解有机质, 大量消耗沉积 物一水界面的氧气, 特别是夏季温度高于冬季, 更加剧 了微生物的分解作用, 因此草型湖区沉积物的溶氧层 浅于藻型湖区, 且夏季浅于冬季. 另外, 由于冬季缺少 水生植物保护, 草型湖区水动力扰动增强也可能是溶 氧层加深的因素之一.

\section{2 草藻型湖区氮磷营养盐释放差异}

关于蓝藻水华和水生植物对沉积物中营养盐的 释放的影响已开展了不少的研究. 在以往的研究中, 大家关注较多的是磷. 在自然水体中, 沉积物与上覆 水间进行的 $\mathrm{P}$ 交换是 $\mathrm{P}$ 循环中重要的一环. 在浅水湖 泊中, 水体与沉积物间作用强烈, 水生植物也会对其 产生重要影响 ${ }^{[25]}$. 水生植物能通过根系吸收沉积物中 生物有效磷, 有效减少沉积物间隙水中的磷向上覆水 的扩散量, 还通过茎叶拦截、吸附水中的颗粒物质并 通过颗粒物质吸附水中的溶解性磷, 有效降低上覆水 中磷及颗粒物的负荷 ${ }^{[26]}$. 也有研究结果表明, 沉水植 物在存在及其生长过程中, 沉积物上部 $5 \mathrm{~cm}$ 沉积物间

隙水中铵态氮含量逐步降低, 表现出沉积物一水界面氮的释放通量与沉积物生物量存在负相关性 ${ }^{[27]}$. 即使是 根系不发达的黑藻, 也能显著降低上覆水中总磷、溶解性活性磷和溶解性总磷的浓度 ${ }^{[28]}$. 在 20 世纪, 针对 265 个浅水湖泊中 TP 的研究揭示了水体中 P 浓度的季节性波动与水体的营养程度高度相关. 在富营养化系 统中, 水体 TP 在冬、夏两季间差异显著 ${ }^{[29]}$. 中国的湖泊学家在武汉东湖中发现 P 在湖泊中的内循环和蓝藻 水华密切相关 ${ }^{[30]}$. 同时, 专家们还在围隔实验中发现随着蓝藻水华的出现, 沉积物中 $\mathrm{P}$ 的释放量也增加, 因 此假设蓝藻水华的光合作用引起水体 $\mathrm{pH}$ 升高并最终导致对沉积物中 $\mathrm{P}$ (而非 $\mathrm{N}$ ) 的百吸作用 ${ }^{[31]}$. 本研究同 样观察到夏季藻型湖区的蓝藻水华引起水体 $\mathrm{pH}$ 升高, 并且夏季沉积物 $\mathrm{P}$ 显著低于冬季. 特别是表层 $3 \mathrm{~cm}$ 沉积物中 P 浓度随深度变浅而降低, 反应出类似的泵吸作用.

关于沉积物 $\mathrm{P}$ 释放的主要影响因子比较复杂, 一般认为主要包括有机质和 $\mathrm{Fe}$ 等 ${ }^{[32]}$. 而 Trolle 等 ${ }^{[33]}$ 在太 湖的研究发现沉积物 $\mathrm{P}$ 和 $\mathrm{Mn}$ 与有机质都显著相关. 草型湖区中沉积物 $\mathrm{P}$ 和 $\mathrm{Fe}$ 的相关系数在冬、夏两季分 别为 $r=0.793$ 和 $r=0.813$, 高于藻型湖区的 0.265 (冬季) 和 0.599 (夏季). 藻型湖区沉积物 P 和 TOC 在冬、

表 5 草、藻型湖区冬、夏两季沉积物 $\mathrm{P}$ 与 TOC、Fe 和 Mn 相关性

Tab. 5 Correlation matrix between $\mathrm{P}$ and TOC, Fe, Mn in macrophytes and phytoplankton dominated zones in winter and spring

\begin{tabular}{cccc}
\hline 湖区类型 & TOC & Fe & Mn \\
\hline 冬季藻型 & $0.604^{* *}$ & $0.265^{*}$ & $0.867^{* *}$ \\
夏季藻型 & $0.817^{* *}$ & $0.599^{* *}$ & $0.864^{* *}$ \\
冬季草型 & 0.076 & $0.793^{* *}$ & $0.671^{* *}$ \\
夏季草型 & 0.202 & $0.813^{* *}$ & $0.909^{* *}$ \\
\hline
\end{tabular}

**表示在 0.01 水平上差异显著; *表示在 0.05 水平上差 异显著.
夏两季都显著相关 $($ 冬季 $r=0.604$, 夏季 $r=0.817)$, 而在草型湖区却未见相关性 $(r=0.076$ 和 0.202$)$. 可以看出, 水生植 物和浮游藻类对沉积物 $\mathrm{P}$ 的影响效果也 不一样. 本研究和 Trolle 等的结果不一致 的原因可能是, Trolle 等在太湖布设的 8 个点, 其中只有 1 个在草型湖区, 并且混 合所有数据一起分析, 从而掩盖了两类湖 区间存在的差异.

夏季草、藻型湖区沉积物中总氮都低 于冬季, 特别是夏季藻型湖区沉积物中各 层的总氮都显著低于其它, 意味着沉积物 
中释放氮的机制与 $\mathrm{P}$ 不同. 本文认为, 夏季水生植物和大量蓝藻生长利用掉一部分氮是其减少的一个原因, 且由于蓝藻生物量较大导致藻型湖区沉积物中氮减少的更为明显. 另外, 夏季高温引起反硝化速率提高可 能是另一个因素. 有研究表明反硝化作用具有明显的季节性, 与温度和沉积物有机质含量相关 ${ }^{[34-36]}$. 因此, 夏季高温下加速的硝化一反硝化作用加剧了沉积物一水界面系统中氮的释放, 从而降低了沉积物中氮的 含量.

\section{4 参考文献}

[ 1 ] 吴丰昌, 万国江, 蔡玉荣. 沉积物一水界面的生物地球化学作用. 地球科学进展, 1996, 11(2): 191-197.

[ 2 ] Meyers PA, Ishiwatari R. Organic matter accumulation records in lake sediments. In: Lerman A, Imboden D, Gat J eds. Physics and chemistry of lakes. Berlin and Heidelberg: Springer-Verlag, 1995: 279-328.

[ 3 ] Vreca P. Carbon cycling at the sediment-water interface in a eutrophic mountain lake (Jezero na Planini pri Jezeru, Slovenia). Organic Geochemistry, 2003, 34: 671-680.

[ 4 ] 秦伯强, 胡维平, 高 光等. 太湖沉积物悬浮的动力机制及内源释放的概念性模式. 科学通报, 2003, 48 : 1822-1831.

[ 5 ] Partheniades E. Unified view of wash load and bed material. ASCE J Hydraulics Div, 1977, 103: 1037-1050.

[ 6 ] Wenzhöfer H, Holby O, Kohls 0 . Deep penetrating benthic oxygen profiles measured in situ by oxygen optodes. Deep-Sea Research I , 2001, 48: 1741-1755.

[ 7 ] Widdows J, Brinsley MD, Bowley N. A benthic annular flume for in situ measurement of suspension feeding biodeposition rates and erosion potential of intertidal cohesive sediments. Estuarine, Coastal and Shelf Science, 1998, 46 : 27-38.

[ 8 ] Kristensen E. Benthic fauna and biogeochemical processes in marine sediments: Microbial activities and fluxes. In: Blackburn TH, Sorensen J eds. Nitrogen cycling in coastal marine environments. New York: Wiley, 1988 : 275-299.

[ 9 ] Michaud E, Desrosiers G, Mermillod-Blondin F et al. The functional group approach to bioturbation: II. The effects of the Macoma balthica community on fluxes of nutrients and dissolved organic carbon across the sediment-water interface. Journal of Experimental Marine Biology and Ecology, 2006, 337: 178-189.

[10] Lewandowski J, Hupfer M. Effect of macrozoobenthos on two-dimensional small-scale heterogeneity of pore water phosphorus concentrations in lake sediments: A laboratory study. Limnol Oceanogr, 2005, 50: 1106-1118.

[11] Wetzel RG. Detritus, macrophytes and nutrient cycling in lakes. Mem Ist Ital Idrobiol, 1990, 47 : 237-249.

[12] 张 路, 范成新, 王建军等. 太湖草藻型湖区间隙水理化特性比较. 中国环境科学, 2004, 24 (5) : 556-560.

[13] 间云君, 李晓宇, 梁彦龄. 草型湖泊和藻型湖泊中大型底栖动物群落结构的比较. 湖泊科学, 2005, 17 (2): 176-182.

[14] 袁信芳, 赵新燕, 施华宏等. 太湖水/沉积物界面固着藻类的时空分布特征. 农业环境科学学报, 2007, 26 (6): 2287-2291.

[15] Xie LQ, Xie P, Tang HJ. Enhancement of dissolved phosphorus release from sediment to lake water by Microcystis blooms - an enclosure experiment in a hyper-eutrophic, subtropical Chinese lake. Environ Pollut, 2003, 122 : 391-399.

[16] Denis L, Grenz C, Alliot E et al. Temporal variability in dissolved inorganic nitrogen flux at the sediment-water interface and related annual budget on a continental shelf (NW Mediterranean). Oceanoogical Acta, 2001, 24: 85-97.

[17] Boon AR, Duineveld A, Berghuis EM et al. Relationships between benthic activity and the annual phytopigment cycle in near-bottom water and sediment in the Southern North Sea. Estuarine Coastal and Shelf Science, 1998, 46: 1-3.

[18] Grenz C, Cloem J, Hager SW et al. Dynamics of nutrient cycling and related benthic nutrient and oxygen flux during a spring phytoplankton bloom in South San Francisco Bay (USA). Marine Ecology Progress Series, 2000, 197: 67-80.

[19] Koho KA, Langezaal AM, Van Lith YA et al. The influence of a simulated diatom bloom on deep-sea benthic foraminifera and the activity of bacteria: A mesocosm study. Deep-Sea Research I , 2008, 55: 696-719.

[20] 张西科, 张福锁, 毛达如. 水稻根麦铁氧化物胶膜对水稻吸收磷的影响. 植物营养与肥料学报, 1997, 3 (4) : 295299.

[21 ] 刘文菊, 朱永官. 湿地植物根表的铁镇氧化物膜. 生态学报, 2005, 25(2) : 358-363.

[22] Reddy KR, D'Angelo EM. Biogeochemical indicators to evaluate pollutant removal efficiency in constructed Wetlands. Wat Sci Technol, 1997, 35(5) : 1-10. 
[23] 吴振斌, 邱东茹, 贺 锋等. 沉水植物重建对富营养水体氮磷营养水平的影响. 应用生态学报, 2003, 14(8): 1351-1353.

[24] 马 凯, 蔡庆华, 谢志才等. 沉水植物分别格局对湖泊水环境 N、P 的因子影响. 水生生物学报, 2003, 27(3): 231-237.

[25] Qin BQ, Zhu GW. The nutrient forms, cycling and exchange flux in the sediment and overlying water system in lakes from the middle and lower reaches of Yangtze River. Science in China: Series D Earth Sciences, 2006, 49(Supp I) : 1-13.

[26] 马 凯, 蔡庆华, 谢志才等. 沉水植物分布格局对湖泊水环境 N、P 的因子影响. 水生生物学报, 2003, 27(3): 231-237.

[27] 包先明, 陈开宁, 范成新. 沉水植物生长对沉积物间隙水中的氮磷分布及界面释放的影响. 湖泊科学, 2006,18 (5) : 515-522.

[28] Scheffer M. Ecology of shallow lakes. London: Chapman \& Hall, 1998 : 1-357.

[29] Søndergaard M, Jensen JP, Jeppesen E. Internal phosphorus loading in shallow Danish lakes. Hydrobiologia, 1999, 408/ 409: $145-152$.

[30] 谢 平. 浅水湖泊内源磷负荷季节变化的生物驱动机制. 中国科学: D 辑: 地球科学, 2005, 35(S2): 11-23.

[31] Xie LQ, Xie P. Long-term (1956-1999) changes of phosphorus in a shallow, subtropical Chinese lake with emphasis on the role of inner ecological process. Water Research, 2002, 36: 343-349.

[32] 王圣瑞, 金相灿, 赵海超等. 沉水植物黑藻对上覆水中各形态磷浓度的影响. 地球化学, 2006, 35(2): 179-186.

[33] Trolle D, Zhu GW, Hamilton D et al. The influence of water quality and sediment geochemistry on the horizontal and vertical distribution of phosphorus and nitrogen in sediments of a large, shallow lake. Hydrobiologia, 2009, 627 : $31-44$.

[34] Nowicki BL, Requintina E, Keuren DV et al. Nitrogen losses through sediment denitrification in Boston Harbor and Massachusetts Bay. Estuaries, 1997, 20 : 626-639.

[35] Desimone LA, Howes BL. Denitrification and nitrogen transport in a coastal aquifer receiving wastewater discharge. Environmental Science and Technology, 1996, 30: 1152-1162.

[36] Herbert RA. Nitrogen cycling in coastal marine ecosystems. FEMS Microbiology Review, 1999, 23: 563-590. 